\title{
Buprenorphine and a CRF Intagonist Block the Acquisition of Opiate Withdrawal-Induced Conditioned Place Aversion in Rats
}

\author{
Luis Stinus*,', Martine Cador', Eric P Zorrilla ${ }^{2}$ and George F Koob ${ }^{2}$ \\ 'Laboratoire de Neuropsychobiologie des Desadaptations, Universite de Bordeaux II, Bordeaux, Cedex, France; ${ }^{2}$ Department of \\ Neuropharmacology, The Scripps Research Institute, La Jolla, CA, USA
}

\begin{abstract}
Conditioned place aversion in rats has face validity as a measure of the aversive stimulus effects of opiate withdrawal that reflects an important motivational component of opiate dependence. The purpose of the present study was to validate conditioned place aversion as sensitive to medications that will alleviate the aversive stimulus effects of opiate withdrawal in humans, and to extend this model to the exploration of the neuropharmacological basis of the motivational effects of opiate withdrawal. Male Sprague-Dawley rats were implanted with two subcutaneous morphine pellets and 5 days later began place conditioning training following subcutaneous administration of a low dose of naloxone. Animals were subjected to three pairings of a low dose of naloxone (I5 $\mu \mathrm{g} / \mathrm{kg}$, s.c.) to one arm of a three-chambered place conditioning apparatus. Buprenorphine administered prior to each pairing dose-dependently blocked the place aversion produced by precipitated opiate withdrawal. A corticotropin-releasing factor-I ( $C_{\text {RF }}$ ) receptor antagonist (antalarmin) also reversed the place aversion produced by precipitated opiate withdrawal. Antalarmin did not produce a place preference or place aversion by itself in morphine-dependent rats. No effect was observed with pretreatment of the dopamine partial agonist terguride or the selective serotonin reuptake inhibitor fluoxetine. Also, chronic pretreatment with acamprosate (a glutamate receptor modulator used to prevent relapse in alcohol dependence) did not alter naloxone-induced place aversion. Buprenorphine by itself in dependent rats produced a mild place preference at low doses and a mild place aversion at higher doses. These results suggest that buprenorphine blocks the aversive stimulus effects of precipitated opiate withdrawal in rats and provides some validity for the use of place conditioning as a measure that is sensitive to potential opiate-dependence medications. In addition, these results suggest that CRF, antagonists can block the aversive stimulus effects of opiate withdrawal and may be potential therapeutic targets for opiate dependence. Neuropsychopharmacology (2005) 30, 90-98, advance online publication, 12 May 2004; doi: I 0.1038/sj.npp. 1300487
\end{abstract}

Keywords: opiate; withdrawal; CRF; buprenorphine; place aversion; rats

\section{INTRODUCTION}

Opiate addiction long has been thought to involve multiple sources of reinforcement (Wikler, 1973). Opiates produce positive reinforcement, in that animals will readily selfadminister opiates and can maintain stable patterns of this self-administration indefinitely with limited daily access to heroin, without the development of obvious tolerance or major signs of physical dependence (Koob et al, 1984). With chronic use, opiates produce tolerance and dependence. This has been hypothesized to contribute to the motivation

*Correspondence: Dr L Stinus, Laboratoire de Neuropsychobiologie des Desadaptations, Universite de Bordeaux II, UMR-CNRS 554I, Bordeaux, Cedex 33076, France, Tel: + 3355657 I548, Fax: + 335 5690 0278, E-mail: luis.stinus@Inpb.u-bordeaux2.fr

Received 24 November 2003; revised 05 April 2004; accepted I4 April 2004

Online publication: 16 April 2004 at http://www.acnp.org/citations/ Npp04 160403540/default.pdf for continued use and escalation to compulsive use (Koob and Le Moal, 1997). While it is clear that the induction of dependence is not necessary for the initiation of voluntary self-administration of opiates, once drug self-administration is initiated the negative consequences of drug abstinence may motivate the continued administration of the drug to prevent the appearance of a withdrawal or abstinence syndrome (Schulteis et al, 1997).

Opiate withdrawal is associated with aversive effects that have motivational significance (Wikler, 1948, 1973; Wikler and Pescor, 1967). Previous work in our laboratory in rodents has shown that precipitated withdrawal from opiate drugs can be associated with a previously neutral environment producing a place aversion where the animal avoids the environment previously paired with opiate withdrawal. The doses of naloxone required to precipitate a place aversion are below those that produce overt physical or somatic signs of opiate withdrawal (Schulteis et al, 1994). The place aversion response does not require maintenance 
of opiate dependence because its manifestation continues to be present weeks after animals are 'detoxified' (eg up to 16 weeks after the morphine pellets are removed; see Baldwin and Koob, 1993; Hand et al, 1988; Stinus et al, 1990, 2000), which clearly indicates that the memory of withdrawal can have long-lasting effects on behavioral responses.

The development of conditioned aversions to precipitated opiate withdrawal appears to depend on elements of the basal forebrain (Stinus et al, 1990; Frenois et al, 2002; Gracy et al, 2001), and more specifically a connection through the basolateral amygdala (Schulteis et al, 2000). The purpose of the present series of experiments is to validate opiate withdrawal-induced conditioned place aversion as sensitive to medication for the treatment of opiate addiction, and to extend this model to the exploration of the neuropharmacological basis of the motivational effects of opiate withdrawal. Place conditioning has been chosen as the dependent variable because of its reliability, its reproducibility, and its sensitivity.

\section{MATERIALS AND METHODS}

\section{Animals}

A total of 287 male Sprague-Dawley rats (IFFA-CREDO, Lyon, France) weighing 220-240 g at the beginning of the experiments were used. Animals were housed by four in makrolon cages located in a thermoregulated room $\left(22^{\circ} \mathrm{C}\right)$ with a 12/12 h dark-light cycle (lights on from 0800-2000). Food and water were available ad libitum. These conditions were maintained constant during all the experiments. Experiments were performed in accordance with the declaration of Helsinki, the European Communities Council Directives (86/609/EEC, November 24, 1986) and the French Directives concerning the use of laboratory animals (décret no 87-848, October 19, 1987).

\section{Drugs}

Naloxone hydrochloride (N-7758, Sigma, France) was dissolved in isotonic saline and injected subcutaneously. Naloxone was administered at a dose of $15 \mu \mathrm{g} / \mathrm{kg}$, and the dose was calculated as free base $(1 \mathrm{mg}$ of naloxone base $=1.11 \mathrm{mg}$ of naloxone hydrochloride). Buprenorphine hydrochloride (Temgesic $0.3 \mathrm{mg} / \mathrm{ml}$, Schering-Plough, France), S-(-)-terguride hydrogen maleate (T-134, Sigma, France) and fluoxetine hydrochloride (F-132, Research Biochemicals International, Natick, MA, USA) were injected subcutaneously; doses were calculated as the salt form. Acamprosate (Merck Lipha, France) was administered either by intraperitoneal injections or in the drinking water. For subcutaneous or intraperitoneal injections, solvent was isotonic $\mathrm{NaCl}$ solution $(0.9 \%, 1 \mathrm{ml} / \mathrm{kg})$. Terguride was dissolved in a drop of hydrochloride acid $(1 \mathrm{~N})$. Antalarmin hydrochloride, a nonpeptide noncompetitive $\mathrm{CRF}_{1}$ receptor antagonist, was suspended in acidified carboxymethylcellullose $(0.5 \%)$, dissolved in saline $(\mathrm{pH}$ of diluent was 5.5), sonicated, and injected i.p. in a volume of $4 \mathrm{ml} / \mathrm{kg}$ as described previously (Zorrilla et al, 2002). Doses were calculated as the salt form.

\section{Induction of Opiate Dependence}

Morphine dependence was induced by subcutaneous implantation (lower back) under deep anesthesia (halothane/air; induction $4 / 100 \mathrm{~V} / \mathrm{V}$ for $10 \mathrm{~s}$ followed by $1.5 / 100$ $\mathrm{V} / \mathrm{V}$ for $30 \mathrm{~s}$ ) of two slow-release, morphine-containing pellets (each morphine pellet contains $75 \mathrm{mg}$ of morphine base, National Institute on Drug Abuse, Bethesda, MD, USA). As previously shown, full dependence to morphine, as measured by naloxone-precipitated opiate withdrawal, is achieved $24 \mathrm{~h}$ following morphine pellet implantation and remains constant for at least 12 days (Gold et al, 1994). If necessary, morphine pellets were withdrawn under deep anesthesia. Placebo-pelleted rats received placebo morphine pellets also implanted subcutaneously under deep anesthesia.

\section{Conditioned Place Aversion Paradigm}

When dependence is established by subcutaneous implantation of morphine pellets, pharmacologically precipitated opiate withdrawal induces conditioned place aversion, which can be observed at doses of opiate antagonists that produce few if any overt somatic signs of withdrawal. Briefly, the conditioned place aversion apparatus used to induce a reliable aversion consists of three (A, B, and $\mathrm{C}$ ) rectangular boxes $(40 \mathrm{~L} \times 33 \mathrm{~W} \times 34 \mathrm{Hcm})$ spaced at $120^{\circ}$ angles and all accessible from a triangular central compartment. Distinctive visual and tactile cues distinguish the three compartments: the walls and floor coloring (either black dots or black stripes or white), and the floor texture (smooth, medium-rough, or rough). The sensory cues combination that produces a balanced choice are for walls and floor coloring, and floor texture, respectively: (A) black dots, smooth; (B) black stripes, medium-rough; and (C) white, rough. Each compartment is equipped with five infrared photocells spaced $8.5 \mathrm{~cm}$ apart along the longer wall, $3.5 \mathrm{~cm}$ above the floor. This allows automatic detection and recording with a computer of an animal's position at all times. Four apparati are located in a sound-attenuated testing room, with white noise $(75 \mathrm{~dB})$ to further mask external noise, and illuminated by a $15-\mathrm{W}$ red light located $1.5 \mathrm{~m}$ above each apparatus. The experimental protocol consists of three distinct phases: a preconditioning phase, a conditioning phase, and a testing phase.

\section{Preconditioning Phase}

In the preconditioning phase (4 days after the implantation of two pellets of morphine), animals were placed in the central triangular compartment and allowed to explore the apparatus freely for $20 \mathrm{~min}$. Animals showing strong unconditioned aversion (less than $17 \%$ of the session time; ie $200 \mathrm{~s}$ ) or preference (more than $44 \%$ of the session time; ie $530 \mathrm{~s}$ ) for any compartment were discarded (11 rats). For each rat, the two compartments with the most similar time allotments were chosen. One side was randomly chosen to be paired with naloxone and the other side to vehicle. The unassigned compartment either could be the most or the least preferred of the three. Importantly, after the compartment assignments were completed, there were no significant differences between time spent in the naloxone-paired and 
the vehicle-paired compartments during the preconditioning phase. This is an important step in the experimental procedure that avoids any preference bias prior to conditioning.

\section{Conditioning Phase}

In the second phase (conditioning), rats received injection of vehicle on days 5,7 , and 9 postpellet implantation prior to being confined to their preselected, vehicle-paired compartment for $20 \mathrm{~min}$. On days 6,8 , and 10 postpellet implantation, rats received $15 \mu \mathrm{g} / \mathrm{kg}$ s.c. of naloxone immediately prior to confinement in the naloxone-paired compartment for $20 \mathrm{~min}$.

\section{Testing Phase}

The test was conducted on day 11 postconditioning, exactly as in the preconditioning phase (free access to each compartment for $20 \mathrm{~min}$ ) at $24 \mathrm{~h}$ post-testing except where noted. The difference $(\Delta D=D-D 0)$ between the time spent in the drug-paired compartment after conditioning $(D)$ minus the time spent in the same compartment before conditioning (preconditioning test $D 0$ ) reflects the change of preference induced by the drug. A negative score indicates a place aversion, a positive score indicates a place preference. Different independent groups of rats were tested for each drug and each dose.

\section{Experimental Design}

Buprenorphine. Five different drugs were tested using the $24 \mathrm{~h}$ postconditioning: buprenorphine, antalarmin, fluoxetine, terguride, and acamprosate. The testing with buprenorphine in naloxone-treated rats (morphine-naloxone) consisted of 67 rats. The rats were made dependent, divided into groups of at least seven each, pretreated $15 \mathrm{~min}$ prior to naloxone with buprenorphine (days 6,8 , and 10 postpellet implantation) and tested at $24 \mathrm{~h}$ postconditioning in a treatment-free state (see Testing Phase above). Doses of buprenorphine were $0,1,2.5,5,10$, and $20 \mu \mathrm{g} / \mathrm{kg}$, s.c.

To evaluate if buprenorphine by itself in morphinedependent rats produced place preference or place aversion, a separate group of 38 morphine-dependent rats without naloxone (morphine) was tested with different doses of buprenorphine $(10,20,40,80$, and $160 \mu \mathrm{g} / \mathrm{kg}$, s.c.). Buprenorphine was injected on days $6,8,10$ postpellet implantation, $15 \mathrm{~min}$ prior to confinement in the drugpaired compartment for $20 \mathrm{~min}$. Similarly, we tested the effects of two doses of buprenorphine (10 and $20 \mu \mathrm{g} / \mathrm{kg}$, s.c.) in separate groups of nondependent rats (placebo pellet implantation; $n=6$ per group).

Antalarmin, fluoxetine, and terguride. Separate groups of morphine-dependent rats that received naloxone immediately prior to conditioning (morphine-naloxone) also were injected $30 \mathrm{~min}$ before naloxone on days 6,8 , and 10 with antalarmin $(2.5,5,10$, or $20 \mathrm{mg} / \mathrm{kg}$, i.p.; $n=8-12$ per group), fluoxetine $(1 \mathrm{mg} / \mathrm{kg}$, s.c.; $n=9)$, or terguride $(0.4 \mathrm{mg} / \mathrm{kg}$, s.c.; $n=7)$. To evaluate if in dependent rats antalarmin by itself produced place preference or place aversion, a separate group of morphine-dependent rats without naloxone (morphine) was tested with two doses of antalarmin (10 and $20 \mathrm{mg} / \mathrm{kg}$, i.p.; $n=9$ and 8 , respectively). Note that the control group Morph-Nal 15-Vehicle was the same for Figures 1 and 3 and Table 2, representing an average of rats tested in this condition throughout the experiments $(n=21)$.

Acamprosate. Separate groups of dependent rats that received naloxone immediately prior to conditioning (morphine-naloxone) also were treated chronically with acamprosate from day 5 to day 11 postpellet implantation. Chronic administration was used because acamprosate has poor absorption and must be given chronically to attain meaningful brain levels (Mas-Serrano et al, 2000). Rats either were injected with acamprosate $(100 \mathrm{mg} / \mathrm{kg}$, i.p.; $n=8)$ twice daily, once 60 min prior to conditioning tests and again $12 \mathrm{~h}$ later, or orally via the drinking water $(2000 \mathrm{mg} / \mathrm{kg} /$ day, $33 \mathrm{mg} / \mathrm{ml}$ in tap water containing $40 \mathrm{mg} / \mathrm{l}$ of saccharin; $n=8$ ).

Finally, in a separate series of experiments $(n=51)$, we tested the effects of acamprosate on the expression of naloxone-induced place aversion in morphine-dependent rats (morphine-naloxone). Potential antiexpression effects of acamprosate were explored because of its glutamatemodulating neuropharmacological effects and its use as an antirelapse medication (Spanagel and Zieglgansberger, 1997). In these experiments, following the conditioning phase (day 5-day 10), morphine pellets were withdrawn on day 11 , and rats were chronically treated with acamprosate from day 18 to day 24 and finally tested for place aversion conditioning on day 24 . Rats received either acamprosate twice daily $(100 \mathrm{mg} / \mathrm{kg}$, i.p.; $n=11)$ or vehicle $(1 \mathrm{ml} / \mathrm{kg}$, i.p.; $n=27$ ) or acamprosate in the drinking water at the dose of $1000 \mathrm{mg} / \mathrm{kg} / \mathrm{day}(16.5 \mathrm{mg} / \mathrm{ml}$ in tap water containing $20 \mathrm{mg} / \mathrm{l}$ of saccharin; $n=6)$, or $2000 \mathrm{mg} / \mathrm{kg} /$ day $(33 \mathrm{mg} / \mathrm{ml}$ in tap

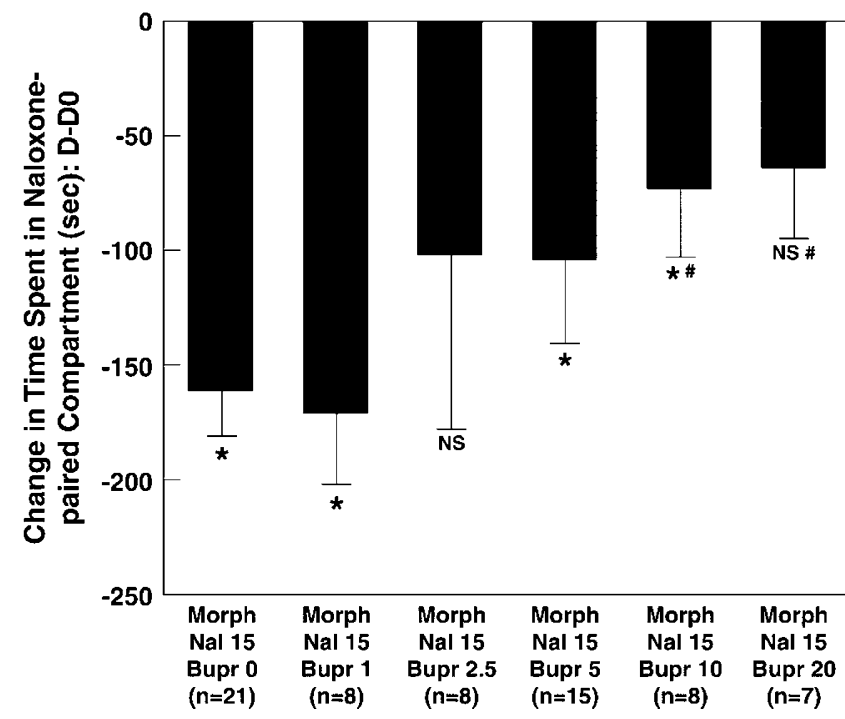

Figure I Buprenorphine dose-dependently inhibited naloxone-precipitated place aversion conditioning in morphine-dependent rats. Within treatment, Wilcoxon signed ranks test ( $D$ vs D0: mean \pm SEM), $p<0.05$; NS refers to no significant place preference or place aversion with the Wilcoxon signed ranks test; between-group comparison, Mann-Whitney test $(\Delta D)$, \#p<0.05 compared to Morph-Nal I 5 group. 
water containing $40 \mathrm{mg} / \mathrm{l}$ of saccharin; $n=7)$. These rats were tested 2 weeks postconditioning. In the present experiments, acamprosate intake was measured by weighing the drinking bottle every 2 days. At the time of the experiment, the mean rat weight was $330 \mathrm{~g}$, and the mean daily intake was $20 \mathrm{ml} /$ day for both solutions of acamprosate.

Additional control groups were tested. A separate group of morphine-dependent rats received saline prior to conditioning (morphine-saline, $n=12$ ). The effects of naloxone or saline prior to conditioning in separate groups of nondependent rats also were tested (placebo pelletsnaloxone, $n=12$; placebo pellets-saline, $n=7)$. The doses of terguride, fluoxetine, and acamprosate were chosen because of the effectiveness of these doses in modulating the reinforcing effects of other drugs of abuse. Also, the treatment interval varied between drugs based on their pharmacokinetic differences (see Spanagel et al, 1996a,b, 1998; Porrino et al, 1989; Cole et al, 2000; Pulvirenti et al, 1998).

\section{Statistical Analysis}

Statistical verification of the preconditioning data was based on the Friedman test. The distribution of the time spent in the three compartments before the conditioning phase was compared to the distribution of the time spent in these same compartments during the test. Establishment of a significant aversion for each group ( $D$ vs $D 0$ ) was tested with the nonparametric Wilcoxon signed ranks test. Then, for each pharmacological treatment, a Kruskal-Wallis nonparametric analysis of variance was performed to test place aversion conditioning $(D-D 0)$ on a logical grouping of means (eg specific drug treatment), and a Mann-Whitney test was performed for comparisons between groups.

\section{RESULTS}

\section{Preconditioning}

As expected, during the preconditioning phase, the preference for the three compartments (A, B, and C) was slightly uneven $(n=287$, Friedman, $\mathrm{F}=4.01, p<0.05)$. The rank order of preference was for black-dotted walls and smooth floor (A; $402 \pm 5 \mathrm{~s})$, for black-striped walls and medium rough floor $(\mathrm{B} ; 403 \pm 5 \mathrm{~s})$, and for white walls and rough floor $(\mathrm{C} ; 386 \pm 5 \mathrm{~s})$. Pairwise comparisons indicated statistical differences $(\mathrm{A} / \mathrm{C}$ and $\mathrm{B} / \mathrm{C}, p<0.05)$. After the allocation of the compartments, the time spent before conditioning in the naloxone-paired $(D 0)$, saline-paired $(S 0)$, and neutral-paired (N0) compartments was significantly different (Friedman test; $\mathrm{F}=35, p<0.0001$ ). Pairwise comparisons showed that $D 0(405 \pm 3 s)$ and $S 0(408 \pm 5 s)$ were identical, but were both significantly different from No (382 $\pm 6 \mathrm{~s} ; p<0.001$ in both cases). Thus, the compartments chosen for the conditioning phase were balanced, and there was no bias before the conditioning phase.

\section{Buprenorphine}

Naloxone at a dose of $15 \mu \mathrm{g} / \mathrm{kg}$ injected subcutaneously to morphine-dependent rats produced a robust place aversion in placebo-injected animals tested $24 \mathrm{~h}$ after the last naloxone pairing session (see Figure 1). This place aversion was dosedependently blocked by pretreatment with buprenorphine $15 \mathrm{~min}$ before the naloxone injections, reaching significance at a dose of $20 \mu \mathrm{g} / \mathrm{kg}$. Buprenorphine administered alone $15 \mathrm{~min}$ prior to testing in morphine-dependent rats produced a modest place preference at the lowest dose of $10 \mu \mathrm{g} / \mathrm{kg}$ but a reversal of the place preference as the dose increased (see Figure 2). Buprenorphine alone in nondependent rats also produced a modest place preference at $10 \mu \mathrm{g} / \mathrm{kg}$, but no effect at $20 \mu \mathrm{g} / \mathrm{kg}$ in nondependent rats (D-D0: $108 \pm 60$ and $20 \pm 15 \mathrm{~s}$, respectively).

\section{Antalarmin}

In morphine-dependent rats, antalarmin by itself at doses of 10 and $20 \mathrm{mg} / \mathrm{kg}$ did not produce either place preference or place aversion (see Table 1). Antalarmin dose dependently inhibited naloxone-induced conditioned place aversion in morphine-dependent rats (Figure 3; Kruskal-Wallis,

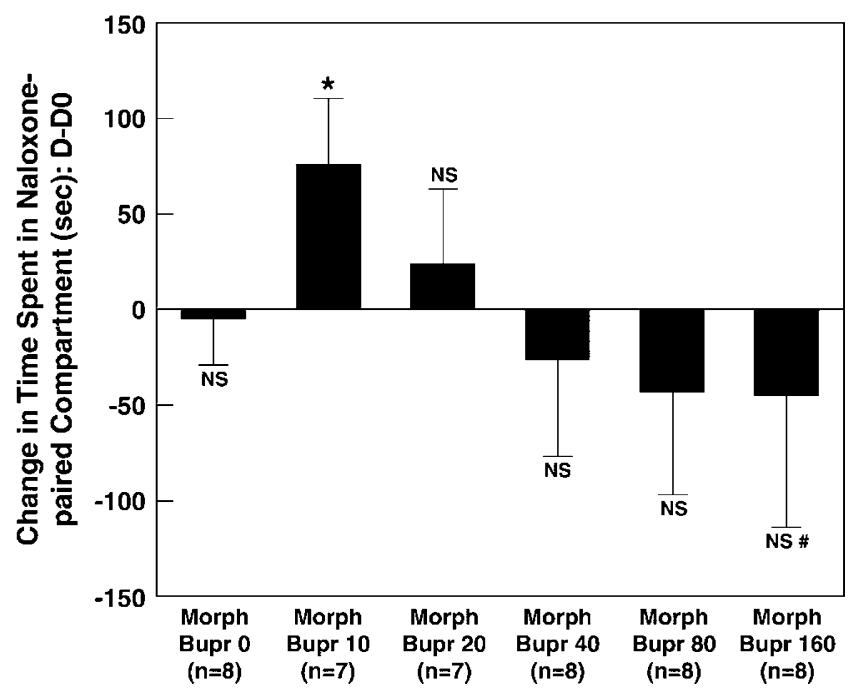

Figure 2 Effects of buprenorphine alone on conditioned place preference/aversion in morphine-dependent rats. Within treatment, Wilcoxon signed ranks test ( $D$ vs $D 0$ ), * $p<0.05$; NS refers to no significant place preference or place aversion with the Wilcoxon signed ranks test; between-group comparison, Mann-Whitney test (D-DO: mean \pm SEM), $\# p<0.05$ compared to Morph_Bupr 10 group.

Table I Effects of Antalarmin on the Acquisition of Place Conditioning in Morphine-Dependent Rats without Naloxone Treatment

\begin{tabular}{lcc}
\hline Condition & n & $\begin{array}{c}\text { Mean change in time spent } \\
\text { ( } \pm \text { SEM) in naloxone-paired } \\
\text { compartment (s): D-D }\end{array}$ \\
\hline Morph-0-Vehicle & 7 & $-5 \pm 24$ \\
Morph-0-Antalarmin 10 & 9 & $-30 \pm 26^{\mathrm{NS}}$ \\
Morph-0-Antalarmin 20 & 8 & $23 \pm 54^{\mathrm{NS}}$ \\
\hline
\end{tabular}

NS, no significant place preference or place aversion across all groups (KruskalWallis) or in pairwise comparisons (Wilcoxon signed ranks test). 
$p<0.001)$. While antalarmin at doses of 2.5 and $5 \mathrm{mg} / \mathrm{kg}$ was ineffective (Mann-Whitney U-test, NS; Morph- Nal 15-Ant 0 compared to both Morph-Nal 15-Ant 2.5 and Morph-Nal 15-Ant 5), doses of 10 and $20 \mathrm{mg} / \mathrm{kg}$ blocked the place aversion produced by naloxone in morphine-dependent rats (Mann-Whitney $U$-test, $p<0.01$; Morph-Nal 15-Ant 0 compared to both Morph-Nal 15-Ant 10 and Morph-Nal 15-Ant 20) and returned values to levels observed with naloxone in placebo-pelleted

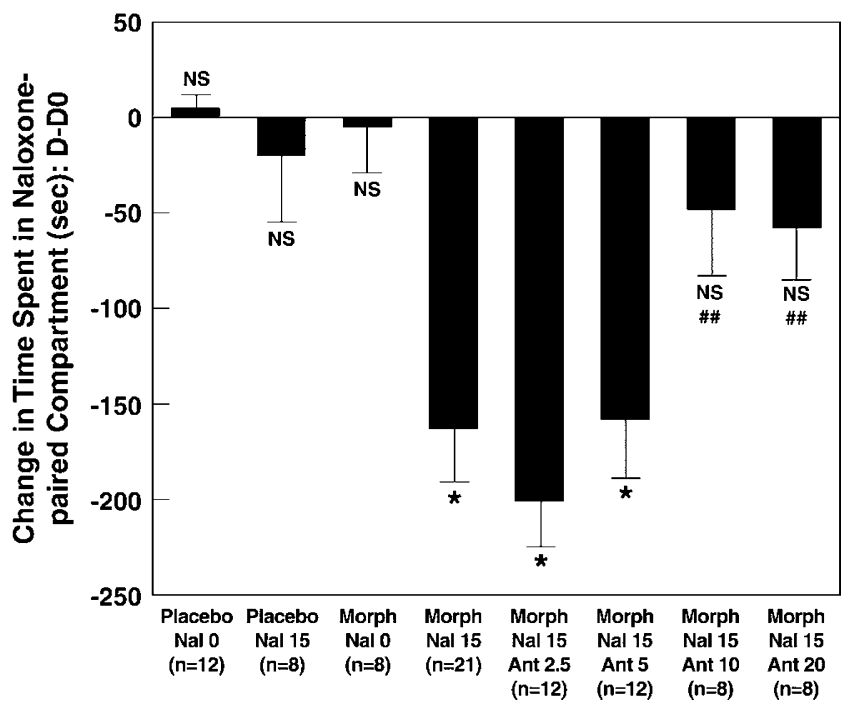

Figure 3 Antalarmin reduced naloxone-precipitated place aversion conditioning in morphine-dependent rats. Within each dose group treatment, Wilcoxon signed ranks test ( $D$ vs $D 0)$, * $p<0.05$; NS refers to no significant place preference or place aversion with the Wilcoxon signed ranks test; between-group comparison, Mann-Whitney test (D-DO: mean \pm SEM), \#\#p<0.0I compared to Morph-Nal 15 group. Note that the Morph-Nal 15 group is the same as in Figure I.

Table 2 Effects of Fluoxetine, Terguride, and Chronic Acamprosate on the Acquisition of, and Chronic Acamprosate on the Expression of, Naloxone-Precipitated Place Aversion in Morphine-Dependent Rats

\begin{tabular}{|c|c|c|}
\hline Condition & n & $\begin{array}{l}\text { Mean change in time } \\
\text { spent ( } \pm \text { SEM) in } \\
\text { naloxone-paired } \\
\text { compartment (s): } D-D 0\end{array}$ \\
\hline \multicolumn{3}{|l|}{ Acquisition } \\
\hline Morph-Nal 15-Vehicle & 21 & $-161 \pm 20^{a}$ \\
\hline Morph-Nal 15-Fluoxetine & 9 & $-160 \pm 49^{a}$ \\
\hline Morph-Nal 15-Terguride & 7 & $-138 \pm 17^{\mathrm{a}}$ \\
\hline Morph-Nal 15-Acamp 100 (i.p. $\times 2$ ) & 8 & $-157 \pm 17^{a}$ \\
\hline Morph-Nal I5-Acamp 200 & 8 & $-185 \pm 15^{a}$ \\
\hline \multicolumn{3}{|l|}{ Expression } \\
\hline Morph_Nal 15_-Vehicle & 27 & $-176 \pm 16^{a}$ \\
\hline Morph-Nal I5-Acamp 100 (i.p. $\times 2$ ) & 11 & $-|25 \pm 3|^{a}$ \\
\hline Morph-Nal I5-Acamp 1000 (oral) & 6 & $-152 \pm 45^{a}$ \\
\hline Morph-Nal I5-Acamp 2000 (oral) & 7 & $-138 \pm 21^{\mathrm{a}}$ \\
\hline
\end{tabular}

${ }^{a}$ Within-treatment, Wilcoxon signed ranks test ( $D$ vs $D 0$ ). rats and in Morph-Nal 0 rats (Mann-Whitney $U$-test; Figure 3).

\section{Acamprosate, Fluoxetine, and Terguride}

Fluoxetine at a dose of $1 \mathrm{mg} / \mathrm{kg}$ and terguride at a dose of $0.4 \mathrm{mg} / \mathrm{kg}$ had no effect on the formation of naloxoneprecipitated place aversion (Table 2). Also, acamprosate administered either i.p. at $100 \mathrm{mg} / \mathrm{kg}$ twice daily or orally in the drinking water at a daily dose of $2000 \mathrm{mg} / \mathrm{kg}$ had no effect on the acquisition of place aversion produced by $15 \mu \mathrm{g} / \mathrm{kg}$ naloxone injected s.c. (see Table 1). Similar negative results were obtained with acamprosate at $100 \mathrm{mg} / \mathrm{kg}$ i.p. twice daily or 1000 and $2000 \mathrm{mg} / \mathrm{kg}$ orally in rats tested 2 weeks postconditioning (data not shown).

\section{DISCUSSION}

The present results show that buprenorphine administered prior to each pairing dose-dependently blocked the place aversion produced by precipitated opiate withdrawal. The selective $\mathrm{CRF}_{1}$ antagonist antalarmin also blocked the place aversion produced by naloxone in morphine-dependent rats. No effect was observed with pretreatment of the dopamine partial agonist terguride or selective serotonin reuptake inhibitor fluoxetine. Also, chronic pretreatment with acamprosate, even at very high doses, did not alter naloxone-induced place aversion. Buprenorphine by itself in dependent rats produced a mild place preference at low doses and a mild place aversion at high doses. These results suggest that buprenorphine reverses the aversive stimulus effects of precipitated withdrawal in rats and provides some validity for the use of place conditioning as a measure sensitive to potential opiate-dependence medications. These results also provide additional evidence for a key role for CRF in the aversive stimulus effects of opiate withdrawal.

Buprenorphine is an opioid partial agonist at the $\mu$ opioid receptor and a $\kappa$ opioid antagonist (Cowan et al, 1977). Buprenorphine's partial agonist properties limit its abuse liability (Jasinski et al, 1978), and it recently has been approved for use in the treatment opiate dependence (Johnson and McCagh, 2000; Tzschentke, 2002; Substance Abuse and Mental Health Services Administration, 2002). Buprenorphine has high affinity for the $\mu, \partial$, and $\kappa$ opioid receptors but moderate intrinsic activity (Cowan, et al, 1977). Buprenorphine produces antinociception in animal models with a potency at least $25 \times$ that of morphine (Cowan, et al, 1977), but the dose-effect function is a Ushaped curve (Lizasoain et al, 1991). Buprenorphine also produced an inverted dose-response function for respiratory depression (Walsh et al, 1995) and gastrointestinal transit (Cowan, 1992). The present data showing a tendency for a place preference at low doses of buprenorphine in dependent rats (high opioid tone), but a place aversion at higher doses, also may reflect its partial agonist properties. However, in the presence of very low opioid tone during precipitated opioid withdrawal, quite low doses of buprenorphine block the conditioned place aversion produced by naloxone in opiate-dependent rats. Buprenorphine is selfadministered by primates but has less efficacy than full agonists and produces less withdrawal (Mello et al, 1981; 
Lukas et al, 1983). Together, these results show that buprenorphine can be limited in its abuse potential (eg low efficacy in producing place preference in opioiddependent or nondependent rats), but effective in blocking the negative affective state associated with withdrawal. Such a profile supports its use in the current clinical setting as a treatment for opiate dependence.

CRF function, outside of the hypothalamic-pituitaryadrenal (HPA) axis, also is activated during acute withdrawal from opiates and other drugs of dependence, including cocaine, alcohol, opiates, and tetrahydrocannabinol, and thus may mediate some of the motivational effects associated with acute abstinence (Heinrichs et al, 1995; Koob et al, 1994; Richter and Weiss, 1999; Rodriguez de Fonseca et al, 1997). For example, animals exposed to chronic cocaine and alcohol show significant anxiety-like responses following cessation of chronic drug administration, which are reversed with intracerebroventricular administration of a CRF antagonist (Rassnick et al, 1993; Sarnyai et al, 1995). Microinjections into the central nucleus of the amygdala of lower doses of the CRF antagonist also reversed the anxiogenic-like effects of alcohol withdrawal (Rassnick et al, 1993), and similar doses of the CRF antagonist injected into the amygdala were active in reversing opiate-induced conditioned place aversion (Heinrichs et al, 1995). Studies using in vivo microdialysis have shown that rats withdrawn from chronic alcohol, withdrawn from chronic cocaine, and precipitously withdrawn from chronic cannabinoids show increases in the release of CRF from the central nucleus of the amygdala (Cummings et al, 1983; Merlo-Pich et al, 1995; Rodriguez de Fonseca et al, 1997). Particularly intriguing are recent studies demonstrating a role for norepinephrine in the bed nucleus of the stria terminalis in the conditioned place aversions associated with opiate withdrawal (Delfs et al, 2000). Because norepinephrine may release $\mathrm{CRF}$ in the basal forebrain, and CRF activates norepinephrine function in the pons, there is the possibility of a feedforward system involved in the aversive stimulus effects of opiate withdrawal as well as stress in general (Koob, 1999; Valentino et al, 1993).

CRF also has been implicated in the reinstatement of heroin- and cocaine-seeking behavior associated with stressor exposure in rats (Shaham et al, 1997, 1998). In rats trained to self-administer heroin intravenously and subjected to extinction, exposure to a mild footshock reinstated responding for heroin, and this responding was blocked by a receptor subtype nonspecific CRF antagonist and a $\mathrm{CRF}_{1}$ antagonist (Shaham et al, 1997, 1998). Similar effects were observed using the conditioned place preference model where both a nonspecific CRF antagonist and a selective $\mathrm{CRF}_{1}$ antagonist, but not a $\mathrm{CRF}_{2}$ antagonist, blocked the stress- and morphine-induced reinstatement of place preference following a 28-day extinction ( $\mathrm{Lu}$ et al, $2000 \mathrm{a}, \mathrm{b})$. The $\mathrm{CRF}_{1}$ antagonist, but not the $\mathrm{CRF}_{2}$ antagonist, also attenuated many of the somatic signs of acute precipitated opiate withdrawal. The present study showing a blockade of the acquisition of place aversion produced by precipitated opiate withdrawal by a selective $\mathrm{CRF}_{1}$ antagonist demonstrates that the effects of CRF antagonists extend to the motivational effects of opiate withdrawal, and that CRF might contribute to the development of opiate dependence in addition to mediating specific aspects of stress-induced modulation of opiate dependence. Antalarmin had no effect of its own in producing place conditioning, an observation consistent with the lack of a place preference with $\mathrm{CP}-154,526$, a structurally similar $\mathrm{CRF}_{1}$ antagonist (Lu et al, 2003). It is unknown whether a CRF antagonist would block the expression of opiate withdrawalinduced place aversion, and expression of withdrawal might involve memory as well as motivational components.

These same central CRF systems are well documented to contribute to behavioral responses to stressors (Koob et al, 1994; Koob and Heinrichs, 1999). When injected intracerebroventricularly, CRF is aversive and produces place aversions (Cador et al, 1992) and taste aversions (Heinrichs et al, 1991) and raises brain stimulation reward thresholds (Macey et al, 2000). In addition, high circulating levels of glucocorticoids can feedback to shut off the HPA axis and can 'sensitize' the CRF systems in the central nucleus of the amygdala known to be involved in behavioral responses to stressors (Lee et al, 1994; Schulkin et al, 1994; Shepard et al, 2000). Thus, concomitant activation of the HPA axis ultimately can lead to activation of brain stress systems. Such activation may contribute to the aversive stimulus state of opiate withdrawal that dissipates with time, but with repeated administration of drug grows larger with time (or fails to return to normal homeostatic baseline), setting up a potential negative reinforcement mechanism (Koob and Le Moal, 2001). It should be noted that the present study used systemic administration of a CRF antagonist that also may block the HPA axis response to stress. As such, the direct link to extrahypothalamic receptors cannot be stated with certainty, although antalarmin at doses that blocked shockinduced freezing did not compromise HPA axis responses to stress (Deak et al, 1999), and in clinical study the $\mathrm{CRF}_{1}$ antagonist R121919 produced anxiolytic-like effects in depressed patients in the absence of effects on basal or CRF-stimulated HPA axis measures (Zobel et al, 2000).

In the present study, acamprosate, a medication currently being used to prevent relapse in alcoholism, had no effect, even at extremely high doses $(2000 \mathrm{mg} / \mathrm{kg}$, p.o.). Acamprosate has been shown in animal models to block the excessive drinking associated with deprivation, dependence, and individual differences (Gewiss et al, 1991; Boismare et al, 1984; Le Magnen et al, 1987; Spanagel et al, 1996a; Holter et al, 1997; Heyser et al, 1998), and in humans has been shown in several multicenter clinical trials to increase abstinence and prevent relapse in detoxified alcoholics (Mason, 2001). Acamprosate also has some effects in preventing aversive effects associated with ethanol withdrawal (Spanagel et al, 1996b; Cole et al, 2000). In vitro studies have suggested that acamprosate may be acting as a partial co-agonist at the $\mathrm{N}$-methyl-D-aspartate receptor (Spanagel and Zieglgansberger, 1997; Zeise et al, 1993; Dahchour et al, 1998; Koob et al, 2002; al Qatari et al, 1998; Naassila et al, 1998), a neuropharmacological action that might explain its blockade of excessive drinking and attenuation of the motivational effects of abstinence from ethanol. The present study was initiated to test the hypothesis that the anti-alcohol-dependence effects of acamprosate might generalize to opiate dependence. Indeed, one study showed that acamprosate attenuated the locomotor sensitization associated with repeated opiate administration (Spanagel et al, 1998). Acamprosate also did 
not alter the expression of opiate withdrawal-induced place aversion. The negative results reported here suggest that acamprosate does not have anti-opiate-dependence effects. These results actually are consistent with studies showing that acamprosate does not generalize to morphine in drug discrimination studies and does not block the reinforcing effects of heroin (Pascucci et al, 1999; Spanagel et al, 1998).

The present results with fluoxetine and terguride suggest that other neuropharmacological systems implicated in the acute reinforcing effects of drugs of abuse may not generalize to the motivational effects of opiate withdrawal. Fluoxetine, at a dose shown to block reuptake in rats (Wong et al, 1985) and decrease cocaine self-administration (Porrino et al, 1989), failed to block conditioned place aversion to opiate withdrawal. Similarly, the dopamine partial agonist terguride at a dose that blocks cocaine selfadministration (Pulvirenti et al, 1998), methamphetamine self-administration (O Kitamura, GF Koob, L Pulvirenti, unpublished results), and psychostimulant withdrawal (Orsini et al, 2001) failed to block conditioned place aversion to opiate withdrawal. These results suggest that the neuropharmacological basis of precipitated opiate withdrawal-induced conditioned place aversion may involve recruitment of other neuropharmacological systems outside of the dopamine projections. Potential substrates involve neurotransmitters implicated in aversive motivational effects and localized to the elements of the 'extended amygdala' (Koob et al, 1998) such as norepinephrine (Delfs et al, 2000) and CRF (Heinrichs et al, 1995). The present results with the $\mathrm{CRF}_{1}$ antagonist antalarmin support this hypothesis. Given the known neuroanatomical, synaptic, and functional interaction of norepinephrine and CRF (Koob, 1999; Valentino et al, 1993), it is possible that these systems might be important therapeutic targets that mediate the aversive stimulus effects of opiate dependence.

\section{ACKNOWLEDGEMENTS}

This is publication number 16070-NP from The Scripps Research Institute. This research was supported by National Institutes of Health Grant DA04043 from the National Institute on Drug Abuse (GFK), the University of Bordeaux 2 (LS, MC), the Centre National de le Recherche Scientifique (LS, MC), the Conseil Regional d'Aquitaine (LS, MC), and Merck Lipha (LS and GFK). GFK also has served as a consultant for Merck Lipha. We thank Mike Arends for his help in preparing and editing this manuscript.

\section{REFERENCES}

al Qatari M, Bouchenafa O, Littleton J (1998). Mechanism of action of acamprosate: Part II. Ethanol dependence modifies effects of acamprosate on NMDA receptor binding in membranes from rat cerebral cortex. Alcohol Clin Exp Res 22: 810-814.

Baldwin HA, Koob GF (1993). Rapid induction of conditioned opiate withdrawal in the rat. Neuropsychopharmacology 8: 15-21.

Boismare F, Daoust M, Moore N, Saligaut C, Lhuintre JP, Chretien $\mathrm{P}$ et al (1984). A homotaurine derivative reduces the voluntary intake of ethanol by rats: are cerebral GABA receptors involved? Pharmacol Biochem Behav 21: 787-789.

Cador M, Ahmed SH, Koob GF, Le Moal M, Stinus L (1992). Corticotropin-releasing factor induces a place aversion independent of its neuroendocrine role. Brain Res 597: 304-309.

Cole JC, Littleton JM, Little HJ (2000). Acamprosate, but not naltrexone, inhibits conditioned abstinence behaviour associated with repeated ethanol administration and exposure to a plusmaze. Psychopharmacology 147: 403-411.

Cowan A (1992). Buprenorphine and gastrointestinal transit in rats: effect of naloxone on the biphasic dose-response curve. Clin Exp Pharmacol Physiol 19: 47-49.

Cowan A, Lewis JW, Macfarlane IR (1977). Agonist and antagonist properties of buprenorphine, a new antinociceptive agent. $\mathrm{Br} J$ Pharmacol 60: 537-545.

Cummings S, Elde R, Ells J, Lindall A (1983). Corticotropinreleasing factor immunoreactivity is widely distributed within the central nervous system of the rat: an immunohistochemical study. J Neurosci 3: 1355-1368.

Dahchour A, De Witte P, Bolo N, Nedelec JF, Muzet M, Durbin P et al (1998). Central effects of acamprosate: Part 1. Acamprosate blocks the glutamate increase in the nucleus accumbens microdialysate in ethanol withdrawn rats. Psychiatry Res 82: 107-114.

Deak T, Nguyen KT, Ehrlich AL, Watkins LR, Spencer RL, Maier SF et al (1999). The impact of the nonpeptide corticotropinreleasing hormone antagonist antalarmin on behavioral and endocrine responses to stress. Endocrinology 140: 79-86.

Delfs JM, Zhu Y, Druhan JP, Aston-Jones G (2000). Noradrenaline in the ventral forebrain is critical for opiate withdrawal-induced aversion. Nature 403: 430-434.

Frenois F, Cador M, Caille S, Stinus L, Le Moine C (2002). Neural correlates of the motivational and somatic components of naloxone-precipitated morphine withdrawal. Eur J Neurosci 16: 1377-1389.

Gewiss M, Heidbreder C, Opsomer L, Durbin P, De Witte P (1991). Acamprosate and diazepam differentially modulate alcoholinduced behavioural and cortical alterations in rats following chronic inhalation of ethanol vapour. Alcohol Alcohol 26: 129-137.

Gold LH, Stinus L, Inturrisi CE, Koob GF (1994). Prolonged tolerance, dependence and abstinence following subcutaneous morphine pellet implantation in the rat. Eur J Pharmacol 253: 45-51.

Gracy KN, Dankiewicz LA, Koob GF (2001). Opiate withdrawalinduced Fos immunoreactivity in the rat extended amygdala parallels the development of conditioned place aversion. Neuropsychopharmacology 24: 152-160.

Hand TH, Koob GF, Stinus L, Le Moal M (1988). Aversive properties of opiate receptor blockade: evidence for exclusively central mediation in naive and morphine-dependent rats. Brain Res 474: 364-368.

Heinrichs SC, Britton KT, Koob GF (1991). Both conditioned taste preference and aversion induced by corticotropin-releasing factor. Pharmacol Biochem Behav 40: 717-721.

Heinrichs SC, Menzaghi F, Schulteis G, Koob GF, Stinus L (1995). Suppression of corticotropin-releasing factor in the amygdala attenuates aversive consequences of morphine withdrawal. Behav Pharmacol 6: 74-80.

Heyser CJ, Schulteis G, Durbin P, Koob GF (1998). Chronic acamprosate eliminates the alcohol deprivation effect while having limited effects on baseline responding for ethanol in rats. Neuropsychopharmacology 18: 125-133.

Holter SM, Landgraf R, Zieglgansberger W, Spanagel R (1997). Time course of acamprosate action on operant ethanol selfadministration after ethanol deprivation. Alcohol Clin Exp Res 21: 862-868.

Jasinski DR, Pevnick JS, Griffith JD (1978). Human pharmacology and abuse potential of the analgesic buprenorphine: a potential agent for treating narcotic addiction. Arch Gen Psychiatry 35: 501-516. 
Johnson RE, McCagh JC (2000). Buprenorphine and naloxone for heroin dependence. Curr Psychiatry Rep 2: 519-526.

Koob GF (1999). Corticotropin-releasing factor, norepinephrine and stress. Biol Psychiatry 46: 1167-1180.

Koob GF, Heinrichs SC (1999). A role for corticotropin-releasing factor and urocortin in behavioral responses to stressors. Brain Res 848: 141-152.

Koob GF, Heinrichs SC, Menzaghi F, Pich EM, Britton KT (1994). Corticotropin releasing factor, stress and behavior. Semin Neurosci 6: 221-229.

Koob GF, Le Moal M (1997). Drug abuse: hedonic homeostatic dysregulation. Science 278: 52-58.

Koob GF, Le Moal M (2001). Drug addiction, dysregulation of reward, and allostasis. Neuropsychopharmacology 24: 97-129.

Koob GF, Mason BJ, De Witte P, Littleton J, Siggins GR (2002). Potential neuroprotective effects of acamprosate. Alcohol Clin Exp Res 26: 586-592.

Koob GF, Pettit HO, Ettenberg A, Bloom FE (1984). Effects of opiate antagonists and their quaternary derivatives on heroin self-administration in the rat. $J$ Pharmacol Exp Ther 229: 481-486.

Koob GF, Sanna PP, Bloom FE (1998). Neuroscience of addiction. Neuron 21: 467-476.

Le Magnen J, Tran G, Durlach J, Martin C (1987). Dose-dependent suppression of the high alcohol intake of chronically intoxicated rats by Ca-acetyl homotaurinate. Alcohol 4: 97-102.

Lee Y, Schulkin J, Davis M (1994). Effect of corticosterone on the enhancement of the acoustic startle reflex by corticotropin releasing factor (CRF). Brain Res 666: 93-98.

Lizasoain I, Leza JC, Lorenzo P (1991). Buprenorphine: bell-shaped dose-response curve for its antagonist effects. Gen Pharmacol 22: 297-300.

Lu L, Ceng X, Huang M (2000a). Corticotropin-releasing factor receptor type I mediates stress-induced relapse to opiate dependence in rats. NeuroReport 11: 2373-2378.

Lu L, Liu D, Ceng X, Ma L (2000b). Differential roles of corticotropin-releasing factor receptor subtypes 1 and 2 in opiate withdrawal and in relapse to opiate dependence. Eur $J$ Neurosci 12: 4398-4404.

Lu L, Liu Z, Huang M, Zhang Z (2003). Dopamine-dependent responses to cocaine depend on corticotropin-releasing factor receptor subtypes. J Neurochem 84: 1378-1386.

Lukas SE, Griffiths RR, Brady JV (1983). Buprenorphine selfadministration by the baboon: comparison with other opioids. In: Harris LS (eds). Problems of Drug Dependence 1982: Proceedings of the 44th Annual Scientific Meeting, The Committee on Problems of Drug Dependence, Inc. (series title: NIDA Research Monograph, Vol. 43). National Institute on Drug Abuse: Rockville MD. pp 178-183.

Macey DJ, Koob GF, Markou A (2000). CRF and urocortin decreased brain stimulation reward in the rat: reversal by a CRF receptor antagonist. Brain Res 866: 82-91.

Mason BJ (2001). Treatment of alcohol-dependent outpatients with acamprosate: a clinical review. J Clin Psychiatry 62(Suppl 20): $42-48$.

Mas-Serrano P, Granero L, Martin-Algarra RV, Guerri C, Polache A (2000). Kinetic study of acamprosate absorption in rat small intestine. Alcohol Alcohol 35: 324-330.

Mello NK, Bree MP, Mendelson JH (1981). Buprenorphine selfadministration by rhesus monkey. Pharmacol Biochem Behav 15: 215-225.

Merlo-Pich E, Lorang M, Yeganeh M, Rodriguez de Fonseca F, Raber J, Koob GF et al (1995). Increase of extracellular corticotropinreleasing factor-like immunoreactivity levels in the amygdala of awake rats during restraint stress and ethanol withdrawal as measured by microdialysis. J Neurosci 15: 5439-5447.

Naassila M, Hammoumi S, Legrand E, Durbin P, Daoust M (1998). Mechanism of action of acamprosate: Part I. Characterization of spermidine-sensitive acamprosate binding site in rat brain. Alcohol Clin Exp Res 22: 802-809.

Orsini C, Koob GF, Pulvirenti L (2001). Dopamine partial agonist reverses amphetamine withdrawal in rats. Neuropsychopharmacology 25: 789-792.

Pascucci T, Cioli I, Pisetzky F, Dupre S, Spirito A, Nencini P (1999). Acamprosate does not antagonise the discriminative stimulus properties of amphetamine and morphine in rats. Pharmacol Res 40: 333-338.

Porrino LJ, Ritz MC, Goodman NL, Sharpe LG, Kuhar MJ, Goldberg SR (1989). Differential effects of the pharmacological manipulation of serotonin systems on cocaine and amphetamine self-administration in rats. Life Sci 45: 1529-1535.

Pulvirenti L, Balducci C, Piercy M, Koob GF (1998). Characterization of the effects of the partial dopamine agonist terguride on cocaine self-administration in the rat. J Pharmacol Exp Ther 286: 1231-1238.

Rassnick S, Heinrichs SC, Britton KT, Koob GF (1993). Microinjection of a corticotropin-releasing factor antagonist into the central nucleus of the amygdala reverses anxiogenic-like effects of ethanol withdrawal. Brain Res 605: 25-32.

Richter RM, Weiss F (1999). In vivo CRF release in rat amygdala is increased during cocaine withdrawal in self-administering rats. Synapse 32: 254-261.

Rodriguez de Fonseca F, Carrera MRA, Navarro M, Koob GF, Weiss F (1997). Activation of corticotropin-releasing factor in the limbic system during cannabinoid withdrawal. Science 276: 2050-2054.

Sarnyai Z, Biro E, Gardi J, Vecsernyes M, Julesz J, Telegdy G (1995). Brain corticotropin-releasing factor mediates 'anxietylike' behavior induced by cocaine withdrawal in rats. Brain Res 675: 89-97.

Schulkin J, McEwen BS, Gold PW (1994). Allostasis, amygdala, and anticipatory angst. Neurosci Biobehav Rev 18: 385-396.

Schulteis G, Ahmed SH, Morse AC, Koob GF, Everitt BJ (2000). Conditioning and opiate withdrawal: the amygdala links neutral stimuli with the agony of overcoming drug addiction. Nature 405: 1013-1014.

Schulteis G, Gold LH, Koob GF (1997). Preclinical behavioral models for addressing unmet needs in opiate addiction. Semin Neurosci 9: 94-109.

Schulteis G, Markou A, Gold LH, Stinus L, Koob GF (1994). Relative sensitivity to naloxone of multiple indices of opiate withdrawal: a quantitative dose-response analysis. J Pharmacol Exp Ther 271: 1391-1398.

Shaham Y, Erb S, Leung S, Buczek Y, Stewart J (1998). CP-154,526, a selective, non-peptide antagonist of the corticotropin-releasing factor 1 receptor attenuates stress-induced relapse to drug seeking in cocaine- and heroin-trained rats. Psychopharmacology 137: $184-190$.

Shaham Y, Funk D, Erb S, Brown TJ, Walker CD, Stewart J (1997). Corticotropin-releasing factor, but not corticosterone, is involved in stress-induced relapse to heroin-seeking in rats. J Neurosci 17: 2605-2614.

Shepard JD, Barron KW, Myers DA (2000). Corticosterone delivery to the amygdala increases corticotropin-releasing factor mRNA in the central amygdaloid nucleus and anxiety-like behavior. Brain Res 861: 288-295.

Spanagel R, Holter SM, Allingham K, Landgraf R, Zieglgänsberger W (1996a). Acamprosate and alcohol: I. Effects on alcohol intake following alcohol deprivation in the rat. Eur J Pharmacol 305: $39-44$.

Spanagel R, Putzke J, Stefferl A, Schobitz B, Zieglgansberger W (1996b). Acamprosate and alcohol: II. Effects on alcohol withdrawal in the rat. Eur J Pharmacol 305: 45-50.

Spanagel R, Sillaber I, Zieglgansberger W, Corrigall WA, Stewart J, Shaham Y (1998). Acamprosate suppresses the expression of morphine-induced sensitization in rats but does not affect 
heroin self-administration or relapse induced by heroin or stress. Psychopharmacology 139: 391-401.

Spanagel R, Zieglgansberger W (1997). Anti-craving compounds for ethanol: new pharmacological tools to study addictive processes. Trends Pharmacol Sci 18: 54-59.

Stinus L, Caille S, Koob GF (2000). Opiate withdrawal-induced place aversion lasts for up to 16 weeks. Psychopharmacology 149: 115-120.

Stinus L, Le Moal M, Koob GF (1990). Nucleus accumbens and amygdala are possible substrates for the aversive stimulus effects of opiate withdrawal. Neuroscience 37: 767-773.

Substance Abuse Mental Health Services Administration (2002). Opioid drugs in maintenance and detoxification treatment of opiate addiction: addition of buprenorphine and buprenorphine combination to list of approved opioid treatment medications. Federal Register 68: 27937-27939.

Tzschentke TM (2002). Behavioral pharmacology of buprenorphine, with a focus on preclinical models of reward and addiction. Psychopharmacology 161: 1-16.

Valentino RJ, Foote SL, Page ME (1993). The locus coeruleus as a site for integrating corticotropin-eleasing factor and noradrenergic mediation of stress responses. In: Tache Y, Rivier C (eds). Corticotropin-Releasing Factor and Cytokines: Role in the Stress Response (series title: Annals of the New York Academy of Sciences, Vol. 697). New York Academy of Sciences: New York. pp 173-188.

Walsh SL, Preston KL, Bigelow GE, Stitzer ML (1995). Acute administration of buprenorphine in humans: partial agonist and blockade effects. J Pharmacol Exp Ther 274: 361-372.
Wikler A (1948). Recent progress in research on the neurophysiologic basis of morphine addiction. Am J Psychiatry 105: 329-338.

Wikler A (1973). Dynamics of drug dependence: implications of a conditioning theory for research and treatment. Arch Gen Psychiatry 28: 611-616.

Wikler A, Pescor FT (1967). Classical conditioning of a morphine abstinence phenomenon, reinforcement of opioid-drinking behavior and 'relapse' in morphine-addicted rats. Psychopharmacologia 10: 255-284.

Wong DT, Reid LR, Bymaster FP, Threlkeld PG (1985). Chronic effects of fluoxetine, a selective inhibitor of serotonin uptake, on neurotransmitter receptors. J Neural Transm 64: 251-269.

Zeise ML, Kasparov S, Capogna M, Zieglgansberger W (1993). Acamprosate (calcium acetylhomotaurinate) decreases postsynaptic potentials in the rat neocortex: possible involvement of excitatory amino acid receptors. Eur J Pharmacol 231: 47-52.

Zobel AW, Nickel T, Kunzel HE, Ackl N, Sonntag A, Ising M, Holsboer F (2000). Effects of the high-affinity corticotropinreleasing hormone receptor 1 antagonist R121919 in major depression: the first 20 patients treated. J Psychiatr Res 34: 171-181.

Zorrilla EP, Valdez GR, Nozulak J, Koob GF, Markou A (2002). Effects of antalarmin, a CRF type 1 receptor antagonist, on anxiety-like behavior and motor activation in the rat. Brain Res 952: 188-199. 